\title{
UNFORESEEN EFFECTS OF THE WWW
}

\author{
H. Maurer \\ Institute for Information Systems and Computer Media, \\ Graz University of Technology, Inffeldgasse, Austria \\ Email: hmaurer@iicm.edu \\ Website: www.iicm.edu/maurer
}

\begin{abstract}
The Web has caused a revolution of how we can access information today, how we easily get answers to many problems, and how we learn. However, there are three issues that are often overlooked. First, it is not easy to extrapolate current developments into the future: we will be in for many more surprises than we think. Second, as fast as the Web has developed, other technologies have developed still faster and their impact on society may be just as significant. Third, one must not overlook that the Web also has some inherent dangers that are more and more emerging. With all enthusiasm we have for the Web, we should also be aware of some of the subtle and some of the not so subtle dangers.

In this paper, I will address the first two issues in the introduction, and devote the rest of the paper to some of the perceived dangers of the Web. One example is the loss of privacy (due to many organisations collecting detailed profiles on all of us, but also on organisations, economic developments and other issues), some of the loss of privacy also due to an unheard of exhibitionism in social networks. Also, information on the Web is often trusted much too easily, leading to a distorted view of reality. Many of the communication tools lead to a loss of concentration and understanding, the latter enhanced by the dangerous copy-paste syndrome. As Tara Brabazon has stated, "Researching is replaced by searching". Also, it is often overlooked that the convergence of mobile phones with powerful PCs will give us excellent personal assistants, but will also obviate the need to learn many things humans have had to learn for generations. Thus it seems that we have to completely re-think education and e-Learning: While myriads of attempts are made on HOW to improve teaching with technology, the main issues may rather be WHAT and WHEN we teach, since so much (will be or) is available everywhere at our fingertips. Finally, can we really trust technology, or could it fail us at some stage on a gigantic scale?
\end{abstract}

\section{INTRODUCTION}

Within 20 years the Web has turned from an experiment to a gigantic success. Most information we now access comes from the Web. Some of the biggest companies live or die with the Web (whether it is Google, Yahoo, Amazon, eBay, Wikipedia, MySpace, Microsoft, etc.). Many of us cannot really imagine a life without the Web. The joke that there are three kinds of death in this world: "There is heart death, there is brain death and there is being off the network" is dangerously close to the truth.

Yet despite all the positive facets of the Web (in this paper synonymous with WWW and also Internet) one should not ignore (a) the possibility that startling changes and surprises might be in store for us, that (b) other technologies have developed as fast or even faster with also substantial impact, and that (c) some rather doubtful developments of the Web are already visible.

Point (a) that we should never be too certain that developments will continue on a smooth trajectory is the corner stone of the bestseller (Taleb, 2008). In this book the author N. N. Taleb argues that the development of our life and our society is dominated by more surprises than we tend to believe. Taleb gives many invaluable examples. Let me repeat one of the more funny ones that I believe shows quite clearly what he means.

Consider the life of a turkey, and how the trust of this turkey into the benevolence of the farmer increases over its lifetime. After the initial fear of any animal towards bigger ones and humans, the turkey is more and more lulled into trusting the farmer: food and water is provided every day, the barn is cleaned once in while and filled with fresh straw. Thus, the turkey feels very comfortable and starts to completely trust the farmer. However, one day before Thanksgiving the farmer takes the turkey and chops off its head, to be sold for a family dinner. The turkey did not at all expect such a dramatic change, similar to the fact that people world wide did not expect a dramatic change in banking and in the economic climate that hit us some 9 months ago. 
Taleb (2008) also presents arguments why we are not used to such surprises: because the stone age, cave dwelling human was not confronted with surprises: the attacking mountain lion, the lightening striking a tree, the ache in the stomach that might kill a beloved one, were all dramatic, but not surprises. It is a phenomenon of our urbanised, globalised and technologised world that gigantic surprises are in store for us. The arguments in the book aforementioned carry over to IT and Web developments, of course, hence we should be wary of predictions that are based on smooth and uninterrupted developments!

Point (b) I mentioned in the abstract is the misunderstanding that the Web has developed particularly fast. The Internet/ Web is some 30 years old (depending on when you start counting), but the penetration of TVs after 1960 was equally fast if not faster, and has reached soon into areas of the third world where the Web will still remain non-existent for a while. Still more impressive is the incredible spread of mobile phones: within ten years a degree of saturation was reached far beyond the saturation reached by the Web in 30 years! Also, both TV and mobile phones have probably influenced our society to a degree equal to or greater than the Web. Is there any doubt that TV has changed cultures and moral values on a tremendous scale?

Concerning point (c) I want to distinguish between truly dangerous aspects of the Web that I will discuss in the sections to follow and some things that make us wonder, but are maybe not dangerous: why do we need 50.000 different horoscopes on the Web; why is the same item of Reuters news repeated on thousands of websites; how come "knowledge" in some areas is reported to double every six years, yet information is doubling every year (indicating the same piece of knowledge is repeated endlessly); why is smut information still so prominent, etc. I will not further address those items in what follows, but concentrate on some of the issues that are indeed outright dangerous to us and/ or society and new developments whose impact is still hard to tell.

Points in this category are the loss of privacy and the danger of profiling, the fact that information on the Web is trusted much too easily, that a number of developments are threatening that we see a distorted reality, that the "copy-paste syndrome" has far reaching implications much beyond just plagiarism and that communication tools are threatening our concentration and attention spans. I will discuss these points in the order listed and finish with a look at new technologies that will raise the stakes still more, both in our favour and against us.

\section{LOSS OF PRIVACY AND PROFILING}

When we use services offered over the Web it is clear to us that we are making information about us known to the service providers. Ordering an item from a Web shop will usually reveal our name and address parameters, of one of our credit cards and of our tastes. After all, such services often take pride in giving us recommendations of the type: "many people who have ordered what you ordered in the past have also purchased the following items...". I think that such recommendations are often welcome, even if they sometimes get it wrong, since at e.g. Xmas I may have purchased many things not because they fit my taste, but the taste of those I wanted to give a present to. The danger from profiles compiled on us by such online shops is usually small, even if there are instances when we should be careful: what if ordering certain items reveals strong political or other views, and the shop is contacted by some agency to find out if we are "suitable" for a certain job, a certain position, etc.

The situation gets much more complicated if a company has a set of services so that combining all the information that potentially can be extracted would then give a very detailed profile. The most often mentioned company in this connection is Google (Cont, 2006), and we use Google as the obvious example. However, we want to point out explicitly that our reservations also concern many other companies.

Google is operating a search engine that almost monopolises searching. Statistics show that world-wide Google has managed to capture some $80 \%$ share of the search market. This is in itself worrisome, as this implies also a dominating share in on-line ads, opening the door to arbitrary pricing or preferences. We will return to this later, but want to dwell for a moment longer on how controlling searching already provides lots of power. If we use only searching we believe that we remain kind of anonymous: mind you, the IP address we are working from provides Google with some geographic information on us, and cookies tell Google "here is the same person who has done queries before", even if we are now using our laptop elsewhere. Summarising, just searching usually does not give Google a profile on persons, but it provides information that could be "mined" for advantage. Analysing all queries from some location may well allow one to observe commercial trends whose knowledge can be valuable for investment situations. Since the general public and most companies do not have this kind of information, Google may have a big advantage over competitors!

The reason why Google is often mentioned as one of the biggest dangers for privacy is due to the fact that Google operates many other services like Google Mail, Google Docs, Google Earth, YouTube and others. The first two mentioned do not only provide the identity of the users (and via cookies the search engine thus does know the identity of users even when they believe they are searching anonymously) they also allow Google 
to examine emails written and received, and information stored. At least, as far as Google Mail is concerned, Google has indeed admitted that contents are scanned by some programs and will provide alerts in some cases. Such alerts may be working in our favour when they originate because of words such as "bomb", "attack", "kill", etc., but may work against us when caused by terms such as "stock", "money", "divorce", "very confidential", etc. In addition to such Google services, Google is collecting data on users through other tools. The one that has created most attention is a program called Google Analytics. This is a piece of statistical software that is free, can be installed on any server, and gives detailed information by whom and how the server is used. It is a very nice program with good visualisation of results, and is thus used by many operators of servers as the preferred statistical tool. It has one "small" catch attached to it: it channels information gained also to Google, unless users take extra precautions. A test of the 300.000 most popular web site showed that over $80 \%$ had installed Google analytics ${ }^{1}$. Thus, even users that never use any Google services will deliver a very complete personal profile to Google, since 4 of 5 servers will pass information on all user actions to Google. It has been noted numerous times that companies installing Google analytics may well violate local data protection laws, but those warnings have had little overall effect. Google is "spying" in a similar fashion using its new browser Google chrome and Google Syndication. Therefore it has already been called "the largest detective agency the world has ever had" in $2007^{2}$. For a more general treatment see (Kulathuramaiyer and Balke, 2006).

Before briefly explaining why detailed profiles on users can be of danger to them, it is only fair to mention that Google is not the only culprit. Similar arguments albeit on a somewhat smaller scale apply to Yahoo! and to Microsoft, and indeed apply potentially to most companies that provide software updates over the net. Observe how often you obtain a message "There are new updates for your software xyz". Most often, those updates are really just corrections of errors (but nobody wants to admit this). But more to the point, how can the company at issue know that you have not installed these updates on your computer without looking into your computer? What guarantee do you have that the company has not installed a Trojan long time ago that sends all kinds of information you have on your computer and hard-disks to the company? Yes, we do live in a time when many who may be tempted to spy on us can easily do so. And isn't cloud-computing where much of your information is held on some remote servers a marvellous tool for spying?

There can be no doubt that some companies are collecting information or profiles on users, and on economic relevant developments. This may be done through stealth as described previously or from open social networks where many persons give away information that may well be harmful to them at some later stage, since usually it cannot be erased any more.

Some will say: "So what? I have nothing to hide." This is just not true. Depending on the circumstances, information gathered can potentially be used against persons when they are looking for a job or even for gentle extortion: some politician may not like a photo that seemed harmless ten years back to suddenly become public, etc.

Of course we must also see the big picture: We are currently in a situation where our privacy is more and more threatened not just because of the Web, but also due to leaving traces when paying by credit cards, giving away our position when using mobile phones or GPS, by RFID and NFC devices, by video supervisionbe it by cameras that are mounted or increasingly by drones, i.e. flying cameras-, or cameras hidden in buttons or eye-glasses, a topic explored in my SF book (Maurer, 2006).

\section{TOO MUCH TRUST IN INFORMATION FOUND}

When searching for some information on the Web people tend to accept what they have found as true information, often without looking at other sources and hence having no justification to accept the information at face value. The Greek philosopher Meno already asked Socrates in 389 B.C.: "And how will you enquire, Socrates, into that which you do not know? What will you put forth as the subject of your inquiry? And if you find out what you want, how will you ever know that this is the thing that you did not know?"

Putting the essence of this in more simple terms: How do we know that we have reached the truth when we did not know it to start with?

Suppose we look for the population of the city of Graz, and we find it is 250,000. How do we know that this is the truth? Well, we do not know, and we cannot trust such information unless we can trust the source!

This is also problem with one of the most treasured information resources on the Web, the Wikipedia. The original idea was that everyone could write, but everyone could also correct and rewrite: the massive amount of readers would eventually make sure that a report on every topic would "converge" to the truth. This

\footnotetext{
${ }^{1}$ www.ontraxx.net and http://futurezone.orf.at/stories/284580/

${ }^{2}$ http://www.iicm.tugraz.at/Ressourcen/Papers/dangers_google.pdf
} 
belief in the "Wisdom of Crowds" is very much supported by Surowieki's book (Surowiecki, 2005). The main thesis of the book is that a crowd always knows more than an expert, or a few experts. Surowiecki presents many arguments and nice examples, and the fact that the Wikipedia is as good as it supports his thesis to some extent.

However, the Wikipedia in its original form must only be seen as a good starting point for information, not more. Whatever is found must not be taken at face value but checked carefully against other sources. Although there are some attempts in some countries under way to make sure that contributions are quality controlled, it is my belief that contributions in the Wikipedia cannot be seen as citeable resources. According to rules in academia, to cite a source the author has to be known, the document has to be stable in time, and the document has to be checked by qualified experts.

Notice that over the years, despite its value, a number of shortcomings of Wikipedia have emerged: first, material can be erroneous (but it can also be erroneous in the best reviewed publication; thus, this is not a matter of yes or no, but a matter of percentage); second, material can be incomplete (and this may often be more misleading than a lie: the statement "Germany has two cities with more than 100,000 inhabitants" is of course true, but is misleading, since there are many more cities in Germany of that size!); third, material can be slanderous (the most famous such instance was the Seigenthaler case ${ }^{3}$ which has led to the blocking of completely anonymous contributions); fourth, material often has a strong country bias (the sewing machine has many different inventors if you examine various country versions of the Wikipedia); fifth, information can be contradictory (you may find that a city has $\mathrm{x}$ inhabitants in some case, but if you look up the state the city is in, it has $y$ different from $\mathrm{x}$ inhabitants: this is since there is no unifying hand); sixth, the material in Wikipedia is not citeable as mentioned earlier.

However, the overall quality of the Wikipedia is quite good. Indeed, recent comparisons with major printed encyclopaedias or editor controlled electronic encyclopaedias show that the error rate of Wikipedia is not significantly higher. While this is a reason for jubilation for some, it is reason for despair for others. Andrew Keen (2007) in his book accuses the "democratic attempts in Web2.0" (of which Wikipedia is one phenomenon) of leading to mediocrity. The Wikipedia is as good as "serious" encyclopaedias not because it is so good, but because it has destroyed the large well-checked encyclopaedias like the French, the Britannica, the Brockhaus in Germany, etc. that could not afford extensive research staff when faced with the free competition of Wikipedia. As this is being written, Microsoft Encarta Encyclopaedia has just folded, as triumphant Wikipediots (a term coined by Keen (2007)) are cheering. As all commercial encyclopaedias are folding, so are many printed newspapers who cannot stand the competition of free news either, music industry is endangered by MP3 players for which songs can be downloaded for a few cents, the movie industry may be next, and Amazon may well ring in the beginning of the end of book shops.

Summarising, the Web is a wonderful resource if used with caution, the interactivity of Web 2.0 is great to some extent, but is also threatening significant parts of our culture. I will look at this also from a slightly different angle in the next section.

\section{DISTORTION OF REALITY}

When looking for some information on the web we usually employ a search engine. This will give us a ranked list of often incredibly many search results. Most users will only look at results on the first page, tacitly assuming that those pages contain the "best" results.

This assumption is wrong for two reasons: at best, the results on the first pages are the most popular ones (and there are many ways to define what most popular means); at worst the items come from organisations who have paid for being ranked very high--- surely a big temptation to both organisations who want to be listed prominently, and for any search engine as great vehicle of revenue!

Combining this with the facts mentioned in the previous section (that information found is taken as truth, rather than carefully checked for validity) has lead Stephan Weber (2006) in his book to formulate "we are googeling reality". We believe that the situation is actually still worse: we are not googeling reality, but the fake reality search engines, Wikipedia and the like want us to see as reality.

There is a real danger that our view of reality is distorted by the Web, by the fact that someone with enough money can influence what is written in the Wikipedia (by just hiring enough staff), that democratic decisions are taken on subjects that allow no democratic decisions. There is the famous story that one of the states in the US voted at some stage that the number PI (obtained by dividing the length of the circumference of a circle by the length of its diameter) should be equal to 4 , since the real (transcendental) value $3.14159 \ldots$ was such a nuisance. The story might be just a story, but the point is clear: (a) there are certain facts that cannot be

\footnotetext{
${ }^{3}$ http://en.wikipedia.org/wiki/Seigenthaler_incident
} 
denied (Einstein's relativity theory cannot be voted out just because it is counter-intuitive and complicated) and (b) different people have different views.

For this reason it is good to have many newspapers or news sources: some are known to be conservative, clerical, socialistic, liberal, whatever --- one does know with what kind of coloured glasses reality is presented. What is the colour of the glasses of those responsible for Wikipedia? Nobody knows. So how do we know that e.g. a contribution in Wikipedia on Taiwan was written by a Taiwanese historian, and not but by someone from mainland China ${ }^{4}$ ?

There is still one other aspect one must not neglect: the Web, particular features of Web 2.0 that are attacked by some, including Andrew Keen, lend themselves to spreading rumours and conspiracy theories. Just use Google and search for "conspiracy theory" and you will see what we mean. Maybe N.N. Taleb is right in his famous book that too much information is not useful ${ }^{5}$ ? (Taleb, 2008)

Just to give a concrete impression of how the Web is used for conspiracy theories (and of denials of such) I examined with the help of Dr. Wolfgang Schinagl, one of the leading IT experts at the Chamber of Commerce in Graz, the conspiracy theory that the first US moon landing in 1968 was a fake. At the end of March 2009, we found 260 TMLWF sites ("The Moon Landings Were Faked"), 620 PAN sites ("Pro Apollo Nutters") and 151,000 (!) "Moon Hoax" sites. Although there is fairly reliable objective evidence that the moon landing took place (three astronomic observatories were watching the landing, one in UK illicitly) the debate continues. It is also interesting that the percentage of persons doubting the moon landing in the US rose from $6 \%$ in 1999 to about $29 \%$ presently.

\section{THE COPY AND PASTE SYNDROME}

Schools and universities have more and more problems with students who prepare essays by using material from Websites or blogs. Often, students just copy pieces of information that look relevant and paste them together, without sometimes even understanding them, let alone citing them. How serious the problem is has been pointed out by Weber e.g. in (Weber, 2006). Indeed, his investigations have even lead to the renouncement of a number of academic degrees in both Austria and Germany based on blatant plagiarism.

To fight plagiarism a number of tools that can help by comparing all information publicly accessible on the Web and available in some special databases with essays or thesis handed in. The success of such plagiarism detection techniques is moderate, but it does help to make students aware of the problem, and afraid of being caught red-handed.

A good survey is found in (Maurer, 2006). However, current plagiarism detection techniques have a number of limitations: they work only when comparing a piece of text with material already available electronically, and available publicly. Also, plagiarism detection is not effective across language boundaries, and can be foiled by "anti-anti-plagiarism" software that rewrites a text by replacing words by synonyms and such. For this reason it is the conviction of the authors and others that the only way to effectively combat plagiarism is to install a kind of electronic diary, allowing relevant parties to follow the development of a thesis or such step by step process, see (Kulathuramaiyer and Maurer, 2008).

It is often thought that plagiarism in schools and academia are the main problems caused by the copy and paste syndrome. However, there two other areas where copy-paste turns out to be very dangerous.

First, plagiarism is a problem of concern not just for educational institutions. For them, it is mainly of concern as a method of cheating. In companies, the problem is not so much a problem of cheating but a question of IPR violation. A study purchased by a company or written by an employee that has plagiarised some other work may well lead to complicated litigation for the company, see e.g. (Kulathuramaiyer and Maurer, 2007).

Second, the copy-paste syndrome has consequences not just in the sense of plagiarism. As Brabazon points out in her book (Brabazon, 2007), copy-paste, SMS, blogging and twittering undermines the capacity of "reading with understanding". To put it differently: students who keep reading only small junks of information and who compose essays by mainly copying never learn to read larger segments of complicated text. Thus, Web 2.0 may well be one of the reasons why "high quality literacy" seems to be on the decline.

Brabazon's observations have been supported by an experiment that I have carried out in Graz now for two years. In a course on "Societal Implications of Computer Science" sixteen one-hour talks on various subject

\footnotetext{
${ }^{4}$ We are using this example since rumours had it that for a long time Taiwan's history in the US Wikipedia was indeed influenced by the mainland China version

${ }^{5}$ Taleb mentions the famous experiment that a fuzzy photo of an object is available. Also, there are ten pictures that are fuzzier but are getting closer and closer to the quality of the fuzzy picture. If persons are shown the fuzzy picture a high percentage will recognize the object; if one shows persons the ten pictures that are gradually starting to be better, with the fuzzy picture as final one, the percentage of persons recognizing the object is very small! This phenomenon (that too much information is contra-productive) is based on the fact that humans tend to make up theories early on and will stick to their theories even in the presence of already strong counter arguments. This remarkable phenomenon can be observed very often in real life.
} 
matters are presented by experts. Students are evaluated on the quality of what they write about those talks, and on the quality of their comments on reports of other students. I divided the students into two groups of roughly 120 each: one group ("the essayists") had to write four substantial essays on talks presented, the other group ("the bloggers") had to write at least 16 blog contributions (at least one each) on each topic. Both groups had to write comments on some of the essays written. It came as a bit of shock and dramatically supports Brabazon's theory that the essayists were not just better in writing their comments, but many of the comments written by the bloggers showed that they had not fully understood the essays they were commenting!

\section{LOSS OF CONCENTRATION}

One of the effects of Web-based communication that has been noticed by a number of researchers is that our communication behaviour is undermining coherent thinking and our concentration.

Typical users today are working on their computers, the cell-phone turned on and the Email system running in the background. As they are studying an important problem that would require all their concentration they are not just interrupted by persons coming to their office and by phone calls (as was the case till a few years ago), but they are also interrupted by some SMS message or by a sound, alerting them that a new Email has arrived. Usually, curiosity wins, and they look at the email. While they might answer it (using just a few words, almost as incoherent as in SMSs or in twittering) they realise that a friend is online, so they start a chat, etc. An incredible amount of thinking- and working time is destroyed in this fashion.

We seem to live in a society that is all the time like in a "three ring circus", time-slicing like an operating system, whether this is at work or at home, where we leaf through the newspaper while a TV-show is on, with some running news at the bottom...

Attention spans and concentration are decreasing, and the Web is one of the tools that are partially responsible for this.

\section{CONVERGENCE}

The Web and the PC or Laptop we are working with today will look very obsolete within a few years. What we are going to witness is a rapid convergence of today still partially separated devices. The Future cell-phone will be a phone, a PC, a (video) camera, will supply wireless access to the Web and to digital TV, will act as identity card and payment device, will allow to play games, act as MP3 player and GPS system, will have a number of built-in sensors and clever software for e.g. speech recognition and translation, text to speech and speech to text conversion, software to analyse the video stream coming from the camera, thus allowing gesture recognition, augmented reality applications and the like.

As a matter of fact, much of this is already available if we look at the iPhone or better yet the next generation of cell-phones in the labs of cell-phone companies. However, there are three main bottlenecks:

(1) The software (e.g. for speech to text conversion and translation into other languages or programs for video analysis) are still less than what is desirable (but the performance will continue to increase year by year)

(2) We need better displays than small cell phones can provide

(3) We need larger keyboards than cell-phones can provide, or alternative input devices.

As mentioned above, (1) will resolve itself in an evolutionary way. We believe that (2) and (3) will be resolved by small revolutions. Screen technology may be replaced by one of the following. Possibility one: Eye-glasses that act as screens (by e.g. projecting the image through the pupil directly onto the retina, or by creating a virtual image in front of the eyes; notice that 3D is included in this case "automatically"). Possibility two: Digital ink, as we see it slowly emerging as Kindle from Amazon or as Sony's e-book. Yet the ultimate display could be waver thin and foldable, so one can carry it in a lady's purse or in the pocket of a jacket. Possibility three: An integrated projection device (beamer) like the SHOW pico projector from Microvision ${ }^{6}$ or the Samsung ${ }^{7}$ pico projector for cell-phones.

Concerning input devices, there are also a number of options for the future, from speech recognition, to gesture recognition by the video camera you are wearing, to touch sensitive projected images that could well fit together with the concept of pico projectors.

\footnotetext{
${ }^{6} \mathrm{http} / / /$ www.microvision.com/pico_projector_displays/

${ }^{7}$ http://www.mobilewhack.com/samsung-mp200-pico-projector-for-mobile-phones/
} 
Of course the devices outlined will not just have good wireless Web connectivity, but also terabytes of local storage. Thus, those devices will be very, very powerful personal assistants feeding us with information at our fingertip, and possibly unnoticeable to bystanders, since the sound might go (via the ear piece on our glasses) directly to the ear-bone, and visual information might be presented to our own eyes only.

\section{BARKING UP THE WRONG TREE}

As explained in the last section, we will have very powerful and knowledgeable personal assistants the size of a cell-phone with us all the time.

But then the question arises: What does this mean for what we still have to know? What do we still have to learn? At the moment there are tens of thousands of experiments in e-Learning concentrating on HOW to use computer technology to assist teaching and learning. As laudable as such efforts are, it seems to us that they are to some extent "barking up the wrong tree": they overlook that advances in technology will change what we will have to know. Thus, the important issue may not be HOW to teach using (future) technology but WHAT and WHEN!

What kind of facts will students at universities in law, medicine, geography, etc. still need to learn when all the facts are just one thought away? Do we still need to teach handwriting? Maybe, but if so, it is mainly to hone hand-eye coordination. But should we then not teach pupils to juggle three balls instead? This might be more fun and is as good for hand-eye coordination. How come nobody is doing research on this?

How about teaching how to construct triangles? Maybe, but if so, it is mainly to hone logical thinking. But should we then not teach pupils how to play chess, bridge or Go? This might be more fun and is just as good for logical thinking. How come nobody is doing research on this? How about language teaching? Maybe, but if so, it is not for its usefulness for communicating with other people, but rather because it seems to be a remarkable tool to develop young brains. How come nobody is doing research on this?

I believe one could and should extend this list, and indeed start to investigate the issues behind those questions. Clearly we cannot think without knowing some facts and some techniques. But I doubt we need to teach many things today simply because they might be useful at some stage. Let us teach what is required and maybe social skills that we don't teach today: How can we make sure that our friendships work out? That we are good and humane leaders, etc. This could allow us to reduce the time students have to attend schools, if we agree to (obligatory?) life-long learning, to learning just-in-time, on the job, what and when it is needed.

\section{TOO MUCH TRUST IN TECHNOLOGY?}

I have explained above: something with the functionality mentioned will be with us in 3-5 years. Thus, we will always have a powerful electronic assistant with us. Great, but what does this mean if all devices and networks would suddenly break down for a long time in a large area? Reasonably large scale incidents of this kind have already happened. By law of probabilities, still more substantial breakdowns will occur. Because of this, we should not give up but increase redundancy in our systems, and we should think globally, but at the same time, make sure that all substantial requirements can be satisfied regionally, whether this is food, transportation, medical car, or energy! This is what I am trying to tell everyone in my SF book (Maurer, 2004).

\section{REFERENCES}

A. Keen: The cult of the amateur". Double Day (2007)

T. Brabazon: The University of Google: Education in a (post) information age. Ashgate (2007)

G. Cont: Googling Considered Harmful. US Military Academy West Point (2006)

N. Kulathuramaiyer, W.-T. Balke: Restricting the View and Connecting the Dots. Dangers of a Web Search Engine Monopoly, J.UCS vol. 12, no. 12 (2006), pp. 1731 - 1740

N. Kulathuramaiyer, H. Maurer: Learning Ecosystems for Dealing with the Copy-Paste Syndrome; Journal for Research in Innovative Teaching vol.1, no.1 (2008), pp.1-25

N. Kulathuramaiyer, H. Maurer: Fighting plagiarism and IPR violation: why is it so important? Learned Publishing vol.20, no.4 (2007), 252-258

H. Maurer: Kampf dem Großen Bruder; Freya (2006), see also www.iicm.edu/Xperten 
H. Maurer, F. Kappe, B. Zaka: Plagiarism - A Survey. J.UCS vol. 12, no. 8 (2006), pp. 1050 - 1084

H. Maurer: The Paranet. Freya (2004), see also http://www.iicm.tugraz.at/home/hm_hp/XPERTS/paranet

J. Surowiecki: The Wisdom of crowds. von Anchor Books (2005)

N. N. Taleb: The black swan. Penguin (2008)

S. Weber: Das Google Copy-Paste Syndrom. Teleopolis-Heine (2006) 